\title{
Susceptibility of Vegetatively Propagated Petunia to Tobamovirus Infection and Its Possible Control
}

\author{
J. Cohen and Noga Sikron \\ Center, P.O. Box 6, Bet Dagan 50250, Israel \\ S. Shuval \\ Danziger Flower Farm, Mishmar Hashiva 50277, Israel
}

Department of Virology, Agricultural Research Organization, The Volcani

\section{A. Gera ${ }^{1}$ \\ Department of Virology, Agricultural Research Organization, The Volcani Center, P.O. Box 6, Bet Dagan 50250, Israel}

Additional index words. Petunia $\times$ hybrida, tobamoviruses, ELISA, mechanical transmission, control measures

\begin{abstract}
In this study, 18 Petunia $\times$ hybrida Hort. Volm.-Andr. cultivars were mechanically inoculated with the tobamoviruses tobacco mosaic (TMV) or tomato mosaic virus (ToMV) $\left(20 \mu \mathrm{g} \cdot \mathrm{L}^{-1}\right.$ in 0.05 м sodium phosphate buffer). One and 2 weeks post-inoculation (PI), inoculated and noninoculated upper leaves were harvested and assayed for TMV infection using enzyme-linked immunosorbent assay (ELISA). Local lesions developed on inoculated leaves of 16 cultivars 3-5 days PI. A total of 11 and 16 of the cultivars developed systemic symptoms characteristic of tobamovirus infection 2 weeks after inoculation with TMV and ToMV, respectively. All cultivars were positive in ELISA tests. Large amounts of virus were recovered from the upper, noninoculated leaves of all cultivars, including symptomless plants. Up to $95 \%$ infection by TMV occurred when a sterilized knife was passed through an infected shoot of petunia prior to its being used to remove cuttings from healthy petunia plants. Heat sterilization of knives and/or treatment with $2.8 \mathrm{~g} \cdot \mathrm{L}^{-1} \mathrm{sodium}$ troclosene was very effective in controlling TMV transmission.
\end{abstract}

Vegetatively propagated petunias were recently introduced into the flower market. This ornamental flowering plant is becoming very popular and in great demand for its flower shape, long life, and vigor, as well as the relative ease of cultivation as a bedding plant or balcony ornamental. The introduction of new hybrids through vegetative propagation without appropriate phytosanitary measures led to the epidemic spread and accumulation of virus infections in propagated material and nuclear stocks. Virus problems had not been experienced previously with petunia grown exclusively from seed. Infections have been reported from all countries where vegetatively propagated petunias are cultivated (Bellardi et al., 1996; Lesemann, 1996). Eleven viruses have been detected in naturally infected Petunia, often in mixed infections (Klinkowski, 1968; Sikron et al., 1995); of these, tobamoand potyviruses are the most important.

Received for publication 20 July 1998 . Accepted for publication 15 Oct. 1998. Contribution from the Inst. of Plant Protection, Agricultural Research Organization, The Volcani Center, Bet Dagan, Israel. No. 510/98. This work was supported by the Israel Flower Board and the Danziger "Dan Flower Farm." The cost of publishing this paper was defrayed in part by the payment of page charges. Under postal regulations, this paper therefore must be hereby marked advertisement solely to indicate this fact. ${ }^{1}$ To whom reprint requests should be addressed. phone.: 972-3-9683571;fax:972-3-9604180; e-mail: abedg@netvision.net.il is a high risk of transferring viral diseases during the harvest of cuttings by hand or with harvesting tools (Lawson et al., 1995). An appropriate and effective means of disinfecting cutting tools is therefore necessary to prevent virus transmission. Walkey (1985) reported the use of $3 \%$ to $10 \%$ trisodium phosphate solution as a disinfectant. The objective of the present study was to examine the susceptibility of vegetatively propagated petunia to tobamovirus infection and its possible control. Transmission of TMV to petunia seedlings by contaminated knives, and the effect of disinfectants on virus transmission are also reported.

\section{Material and Methods}

Mechanical inoculation of plants. Fully expanded leaves from 18 petunia cultivars ('Big Spark', 'Blue Spark', 'Bright Dream', 'Casablanca', 'Cascadias Pink', 'Cascadias Red', 'Cascadias Yellow Eye', 'Champagne', 'Chaplin', 'Charisma', 'Charme', 'Cherie', 'Chipper', 'Choice', 'Choppy', 'Happy Dream', 'Pink Spark', and 'Sweet Dream') were dusted with carborundum and mechanically inoculated with $20 \mu \mathrm{g} \cdot \mathrm{mL}^{-1}$ of TMV or tomato mosaic virus (ToMV) in $0.05 \mathrm{M}$ sodium phosphate buffer, $\mathrm{pH}$ 7.0. Both TMV and ToMV were originally isolated from naturally infected petunia (Sikron et al., 1995). Mock-inoculated plants were inoculated with buffer; following inoculation, plants were rinsed with tap water and incubated under greenhouse conditions $\left(23 \pm 3^{\circ} \mathrm{C}\right)$. Both inoculated and noninoculated leaves were harvested from plants that were inoculated with a tobamovirus or plants that were mock-inoculated. Leaf samples were homogenized in 0.05 M phosphate buffer, $\mathrm{pH} 7\left(0.5 \mathrm{~g} \cdot \mathrm{mL}^{-1}\right)$. Sap was rubbed onto carborundum-dusted leaves of Nicotiana benthamiana, $N$. sylvestris, and N. glutinosa (Holmes, 1961) as described cially in vegetatively propagated crops, there
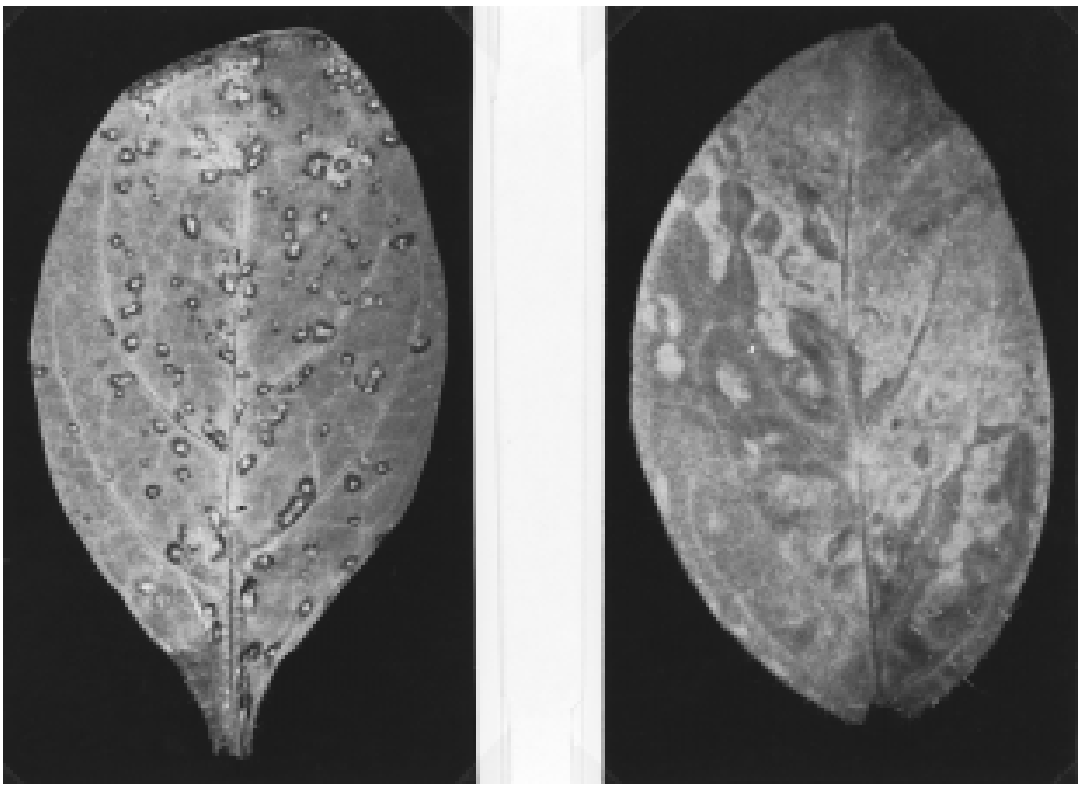

Fig. 1. Petunia plants infected by tobacco mosaic virus (TMV). Necrotic local lesions on mechanically inoculated leaf (left), chlorosis and mosaic on systemic leaf (right). 
above, and the plants were grown in an insectproof greenhouse.

Transmission by contaminated knives. The TMV source was 'Cascadias Yellow Eye' petunia showing typical TMV symptoms. The presence of TMV was confirmed by ELISA and immuno-specific electron microscopy (ISEM) (Milne and Lesemann, 1984). A sterilized knife was passed three times through TMV-infected shoots prior to being used to remove three to four cuttings from healthy, 3week-old 'Blue Spark' petunia seedlings, grown in a greenhouse. The knife was either changed between plants or decontaminated by heating using a dry heat sterilizer with glass beads (Steri 250, Switzerland) or by dipping in a solution of sodium troclosene (Menno Chemie-Vertriebsges M.B.H, Norderstedt, Germany) for $15 \mathrm{~s}$. For each plant, a separate tube filled with the disinfectant solution was used to avoid carryover. After inoculation, the plants were kept in an insect-proof screenhouse for 3 weeks and observed for symptom development. Newly developing leaves were harvested from inoculated plants and tested for TMV by ELISA.

Control treatments consisted of noninoculated seedlings and seedlings mock-inoculated with a knife passed through healthy shoots, disinfected as above, then passed through the recipient seedlings.

ELISA. The double-antibody sandwich (DAS) ELISA was used. Plant extracts were prepared by grinding leaf samples in phosphate-buffered saline (PBS) (150 mm sodium chloride, $150 \mathrm{~mm}$ sodium phosphate) containing $0.02 \%$ Tween- $20,0.2 \%$ polyvinylpyrrolidone, and $0.4 \%$ bovine serum albumin (1 $\mathrm{g} \cdot \mathrm{mL}^{-1}$ buffer). The plates were coated with immunoglobulin $\mathrm{G}(\mathrm{IgG})$ at a concentration of $1 \mu \mathrm{g} \cdot \mathrm{mL}^{-1}$. Alkaline phosphatase conjugates of TMV and ToMV were used at a dilution of 1:1000. Five plants of each cultivar infected with TMV or ToMV were assayed. A negative control consisting of crude sap from healthy plants was included in all assays.

\section{Results and Discussion}

Symptoms of tobamoviruses in naturally infected petunia were quite variable. Infected plants exhibited severe mosaic or mottling (Fig. 1), often combined with leaf deformations and, in some cultivars, color-breaking of flowers. The number and size of flowers produced by infected plants were obviously reduced. Differentiation between TMV and ToMV based on visual symptoms was not possible. The presence of TMV was unequivocally demonstrated by its systemic infection in Nicotiana sylvestris, whereas ToMV produced only necrotic local lesions on this host.

TMV inoculation of petunia. Three expanded leaves on each of the 18 petunia cultivars were mechanically inoculated with either TMV or ToMV. One week PI, necrotic local lesions (Fig. 1) were observed on the inoculated leaves of 16 petunia cultivars; no visible symptoms developed on the inoculated leaves of cvs. Champagne and Chaplin. One and 2 weeks PI, inoculated and noninoculated upper leaves were harvested and assayed for TMV and ToMV infection using ELISA. All cultivars were positive in ELISA (ELISA values were $0.662-2.300$ ). Two weeks PI, systemic symptoms characteristic of tobamovirus infection were observed in the upper leaves of 11 and 16 of the petunia cultivars inoculated with TMV and ToMV, respectively. No visible symptoms developed on the upper leaves of 'Blue Spark', 'BrightDream', 'Cascadias Red', 'Charisma', 'Chipper', 'Happy Dream', and 'Sweet Dream' up to 4 weeks PI with TMV. The petunia cultivars Bright Dream and Charme showed no visible systemic symptoms up to 4 weeks PI with ToMV. Large amounts of virus were recovered from the upper noninoculated leaves of all cultivars, including symptomless plants.

Transmission with contaminated knives. Visual examination of symptoms 2 weeks after inoculation with TMV-contaminated knives showed that the virus was readily transmitted to healthy petunia seedlings. Of 20 knife-inoculated seedlings, 15 (75\%) showed typical TMV symptoms 3 weeks PI, and 19 (95\%) were TMV-positive using ELISA. Sterilization of contaminated knives by sodium troclosene at concentrations of $0.7-1.4 \mathrm{~g} \cdot \mathrm{L}^{-1}$ was partially effective (Table 1 ). However, all plants were TMV-negative when knives were heat sterilized or treated with $2.8 \mathrm{~g} \cdot \mathrm{L}^{-1}$ sodium troclosene for $15 \mathrm{~s}$ (Table 1). All control plants mock-inoculated with sterilized knives were TMV-negative.

Disinfectants successfully used against human viruses usually failed when tested against plant viruses, primarily because plant
Table 1. Effect of using nonsterilized knives on the virus status of petunia cuttings.

\begin{tabular}{lc}
\hline $\begin{array}{l}\text { Method of } \\
\text { sterilization }\end{array}$ & $\begin{array}{c}\text { Incidence of } \\
\text { transmission }^{z}\end{array}$ \\
\hline Non & $19 / 20^{\mathrm{y}}$ \\
Heat & $0 / 20$ \\
Sodium troclosene, $2.8 \mathrm{~g} \cdot \mathrm{L}^{-1}$ & $0 / 20$ \\
Sodium troclosene, $1.4 \mathrm{~g} \cdot \mathrm{L}^{-1}$ & $2 / 20$ \\
Sodium troclosene, $0.7 \mathrm{~g} \cdot \mathrm{L}^{-1}$ & $5 / 20$ \\
\hline
\end{tabular}

${ }^{\mathrm{z}}$ Average of three replicates.

'Number of plants infected/number of slashed seedlings.

viruses are intrinsically more stable and therefore considerably more difficult to inactivate. Since tobamoviruses naturally infecting petunia are almost ubiquitous and readily transmissible to numerous agricultural and horticultural crops, the risk of viral contamination of vegetatively propagated petunia is high if precautions are not taken to prevent infection. As with other vegetatively propagated virussensitive crops, a strict system for maintaining and propagating virus-indexed nuclear stocks has to be developed to control viruses. Because TMV is one of the most stable plant viruses, we believe that if sodium troclosene is effective against TMV, it should be effective against all common viruses infecting petunia.

\section{Literature Cited}

Bellardi, M.G., C. Rubies-Aubies-Autonell, and V. Vicchi. 1996. Virus infections of Surfinia in Italy. Acta Hort. 432:88-94.

Holmes, F.O. 1961. Concomitant inheritance of resistance to several viral diseases in tobacco. Virology 13:409-413.

Klinkowski, M. 1968. Pflanzliche Virologie, vol. II. Die Virosen des europaischen Raumes, Part 2. Akademie-Verlag, Berlin.

Lawson, R., A. Gera, and H.T. Hsu. 1995. Transmission of plant viruses, p. 17-134. In: G. Loebenstein, R.H. Lawson, and A. Brunt (eds.). Viruses and virus-like diseases of bulb and flower crops. Wiley, Chichester, U.K.

Lesemann, D.E. 1996. Viruses recently detected in vegetatively propagated petunia. Acta Hort. 432:88-94.

Milne, R.G. and D.E. Lesemann. 1984. Immunosorbent electron microscopy in plant virus studies. Methods in Virol. 8:85-101.

Sikron, N., J. Cohen, S. Shoval, and A. Gera. 1995. Virus diseases in petunia. Phytoparasitica 23:273. (Abstr.)

Walkey,D.G.A. 1985. Applied plant virology. Wiley, New York. 